\title{
DESENVOLVIMENTO DE PLANTAS DE MARACUJAZEIRO-AMARELO PRODUZIDAS POR ENXERTIA HIPOCOTILEDONAR EM CINCO PORTA-ENXERTOS DE PASSIFLORAS SILVESTRES ${ }^{1}$
}

\author{
GERALDO COSTA NOGUEIRA FILHO ${ }^{2}$, GIVANILDO RONCATTO ${ }^{3}$, CARLOS RUGGIERO ${ }^{4}$, \\ JOÃO CARLOS DE OLIVEIRA ${ }^{4}$, EUCLIDES BRAGA MALHEIROS ${ }^{4}$
}

RESUMO - O experimento foi realizado em área de pequeno produtor fornecedor da Maguari (Kraft Foods do Brasil) em Araguari - MG, e teve por objetivo avaliar o desenvolvimento de maracujazeiro-amarelo propagado por enxertia hipocotiledonar, sobre cinco porta-enxertos de passifloráceas nativas. Os tratamentos utilizados foram cinco porta-enxertos: Passiflora edulis f. flavicarpa, P. caerulea, P. alata, P. gibertii e $P$. cincinnata, e o maracujazeiro-amarelo de pé-franco como controle, totalizando seis tratamentos. Para todos os tratamentos, a variedade-copa utilizada foi o maracujazeiro-amarelo Cv. FB 200. O delineamento experimental utilizado foi o de blocos ao acaso, com três repetições. A parcela foi constituída de uma fileira de 20 metros de comprimento contendo quatro plantas. A condução foi realizada conforme os tratos culturais recomendados para a cultura. As características avaliadas foram: altura das plantas, número de folhas, diâmetro da região da enxertia, diâmetro do enxerto, diâmetro do porta-enxerto, relação enxerto/porta-enxerto. As plantas de $P$. edulis f. flavicarpa, P. caerulea e pé-franco apresentaram melhor desenvolvimento. Já as plantas sobre o portaenxerto $P$. alata não desenvolveram bem. Embora as plantas de pé-franco tenham superado numericamente o desenvolvimento das enxertadas sobre $P$. cincinnata e $P$. gibertii, não houve diferenças significativas entre eles. O porta-enxerto $P$. alata influenciou negativamente na altura das plantas, número de folhas, diâmetro da região da enxertia, diâmetro do enxerto, diâmetro do porta-enxerto e na relação enxerto/porta-enxerto. Termos para Indexação: Passiflora spp., propagação vegetativa, desempenho agronômico.

\section{DEVELOPMENT OF YELLOW PASSION FRUIT PLANT PRODUCED BY HYPOCOTYLEDONARY GRAFTING ON FIVE ROOTSTOCKS OF WILD PASSIFLORA IN ARAGUARI-MG}

\begin{abstract}
The experiment was carried out in an area of a small producer supplier of Maguari (Kraft Foods of Brazil) in Araguari-MG, and aimed to assess the development of yellow passion fruit plant grafted on five rootstocks of native passifloraceas using the hypocotyledonary grafting method. The treatments used as rootstocks were Passiflora edulis f. Alavicarpa, P. caerulea, P. alata, P. gibertii and P. cincinnata. The yellow passion fruit non-grafted seedlings were used as control, completing six treatments. For all treatments, the yellow passion plant FB 200 was used as canopy crown variety. It was used the experimental design randomized blocks with three repetitions. The plot was formed by a line of 20 meters long containing four plants. The passion fruit planting was done according to cultural treatments recommended for this culture. The characteristics evaluated were plant height, number of leaves, diameter of the region of grafting, the scion diameter, diameter of the rootstock, relation between scion and rootstock. The plants of $P$. edulis $\mathrm{f}$. flavicarpa, P. caerulea and the non-grafted seedlings showed better development. Plants of the rootstock $P$. alata had the worst development. Although the non-grafted seedlings have exceeded the development of grafted with $P$. cincinnata e $P$. gibertii, they did not differ significantly from them, and the rootstock $P$. alata negatively influenced on the plant height, number of leaves, diameter of the region of grafting, the graft diameter, diameter of the rootstock, relation between scion and rootstock.

Index terms: Passiflora spp., vegetative propagation, agronomic performance.
\end{abstract}

\footnotetext{
'(Trabalho 147-09). Recebido em: 15-06-2009. Aceito para publicação em: 23-10-2009.

${ }^{2}$ In memorian.

${ }^{3}$ Pesquisador A - Embrapa Acre. Rodovia BR 364 km 14, Zona Rural, Cep 69901180 Rio Branco-AC. E-mail: givanildo@cpafac.embrapa.br ${ }^{4}$ Professores Titulares da Unesp/Fcav. Via de acesso Paulo Donato Castellane, s/n Cep 14884-900 Jaboticabal-SP. E-mail: ruggiero@fcav.unesp.br ; jocaoliv@fcav.unesp.br; euclides@fcav.unesp.br
} 


\section{INTRODUÇÃO}

O Brasil é o primeiro produtor mundial de maracujá com uma produção de $664.286 \mathrm{t}$ anuais e com boas perspectivas para a ampliação da área cultivada que já atingiu 47.032 ha/ano, embora a ocorrência de problemas fitossanitários tenha contribuído, nos últimos anos, para a redução da vida útil dos novos plantios (SIDRA/IBGE, 2009).

A vida útil da lavoura, que pode ser de até cinco anos, vem sendo reduzida principalmente devido aos danos causados por doenças. Em Pernambuco, o ciclo produtivo foi reduzido para um ano e, no Paraná e em Santa Catarina, é de dois anos (LIBERATO, 2002).

A característica mais marcante deste cultivo tem sido a sua itinerância, que é o fato de a cultura surgir, experimentar uma enorme ascensão e quase desaparecer de uma região, num período que tem variado de 3 a 5 anos. Na cultura do maracujazeiro, a enxertia é apontada como método de controle de patógenos habitantes do solo, embora outras vantagens possam advir dessa prática (LIBERATO, 2002). No Brasil, essa prática ainda não é utilizada por falta de dados que comprovem sua viabilidade técnica e econômica.

As espécies Passiflora alata, P. macrocarpa e $P$. quadrangularis possuem caules com diâmetro equivalente ao da espécie comercial, facilitando a enxertia. Tem-se observado boa compatibilidade entre enxerto e porta-enxerto, noutras espécies, entretanto apresentam problemas para a enxertia, por terem caule muito fino (BRUCKNER et al., 2002). Para resolver esta incompatibilidade de diâmetro entre as peças envolvidas na enxertia, Kimura (1994) apresenta a enxertia hipocotiledonar de plântulas de maracujazeiro como viável.

A maioria dos trabalhos encontrados na literatura com enxertia em maracujazeiro atémse à produção de mudas ou às primeiras fases de desenvolvimento das plantas a campo (MENEZES, 1990; STAVELEY; WOLSTENHOLME, 1990; MENEZES et al., 1994; KIMURA, 1994; LIMA et al., 1999; CHAVES et al., 2004). Poucos são os trabalhos que avaliaram características relativas à produção. Além disso, a produção de frutos nas plantas enxertadas não foi superior às produzidas por pé-franco, visto que estas tiveram produtividades semelhantes (MALDONADO, 1991; STENZEL;CARVALHO, 1992; JUNQUEIRA et al., 2006).

Este trabalho teve por objetivo avaliar o desenvolvimento de plantas de maracujazeiroamarelo produzidas por enxertia hipocotiledonar, sobre cinco porta-enxertos de passifloras silvestres, em Araguari - MG.

\section{MATERIAL E MÉTODOS}

O experimento foi realizado em área de pequeno produtor, em Araguari-MG, coordenadas $18^{\circ} 38^{\prime} 30^{\prime \prime} \mathrm{S}$ e $48^{\circ} 11^{\prime} 18^{\prime \prime} \mathrm{W}$, altitude média de $900 \mathrm{~m}$. De acordo com a classificação de Köeppen, o clima é do tipo $\mathrm{Cwb}$, tropical quente e úmido, seco no inverno, temperatura média de $20,7^{\circ} \mathrm{C}$, com máxima de $24,2^{\circ} \mathrm{C}$ e mínima de $20^{\circ} \mathrm{C}$, precipitação média anual de $1.484 \mathrm{~mm}$.

Os tratamentos utilizados foram cinco porta-enxertos: P. edulis f. flavicarpa, $P$. caerulea, $P$. alata, $P$. gibertii, $P$. cincinnata e o maracujazeiroamarelo de pé-franco como controle, totalizando seis tratamentos. Para todos os tratamentos, a variedade-copa utilizada foi o maracujazeiro-amarelo FB 200. O delineamento experimental utilizado foi o de blocos ao acaso, com três repetições. A parcela era constituída de uma linha de 20 metros de comprimento, contendo quatro plantas. O espaçamento utilizado foi de $3 \mathrm{~m}$ entre linhas e $5 \mathrm{~m}$ entre plantas.

Previamente, foi feita a análise de solo da área a instalar-se o pomar, e de acordo com o resultado da análise de solo, verificou-se a necessidade de calagem e adubação. Assim, pH de 4,6; $\mathrm{MO}\left(\mathrm{em} \mathrm{CaCl}_{2}\right)$ de 42 $\mathrm{g} / \mathrm{dm}^{3} ; \mathrm{P}$ (em resina) de $53 \mathrm{mg} / \mathrm{dm}^{3} ; \mathrm{K}$ de 1,$8 ; \mathrm{Ca}$ de 30; $\mathrm{Mg}$ de $12 \mathrm{H}+\mathrm{Al}$ de 72; SB de 43,8, e T de 115,5 $\mathrm{mmol} / \mathrm{dm}^{3} ; \mathrm{V}(\%)=38$ para a calagem e a adubação baseando-se nesta análise e nas recomendações de adubação feitas por Van Raij (1997). A calagem foi feita em área total, conforme análise de solo, visando a elevar a saturação por bases a $\mathrm{V} \%=80$, utilizando calcário calcítico, PRNT 80. O preparo do solo constituiu-se de uma aração profunda $(25 \mathrm{~cm})$ seguida de uma gradagem. Foram feitas covas de $50 \times 50 \times 50 \mathrm{~cm}$.

A adubação de fundação foi de $20 \mathrm{~L}$ de esterco de curral curtido, $450 \mathrm{~g}$ de superfosfato simples e $50 \mathrm{~g}$ de FTE BR 12 por planta. A adubação de formação foi realizada em cobertura, com $250 \mathrm{~g}$ de $\left(\mathrm{NH}_{4}\right) 2 \mathrm{SO}_{4} \mathrm{e}$ $250 \mathrm{~g}$ de $\mathrm{KCl}$ por planta, parcelada em três aplicações espaçadas a cada 30 dias. O plantio foi realizado em 09-04-2002. A adubação de produção foi realizada em cobertura, com $1,6 \mathrm{~kg}$ de $\left(\mathrm{NH}_{4}\right) 2 \mathrm{SO}_{4}$ e $1,6 \mathrm{~kg}$ de $\mathrm{KCl}$, em parcelas iguais, aplicados quinzenalmente por cova, a partir do mês de agosto de 2002 até abril de 2003. Além disso, em 15 de setembro de 2002 , foi feita uma adubação de reforço de produção, com $500 \mathrm{~g}$ de superfosfato simples, $10 \mathrm{~L}$ de esterco de curral curtido e 50g de FTE BR 12 por planta. 
As plantas foram conduzidas em haste única até ultrapassarem o arame da espaldeira $(1,60 \mathrm{~m})$ em cerca de $10 \mathrm{~cm}$, quando foram despontadas para induzir a emissão dos ramos secundários. Estes, por sua vez, foram despontados quando atingiram a planta vizinha, para forçar a emissão de ramos terciários. As plantas foram pulverizadas preventiva e/ou curativamente com produtos à base de cobre metálico (Cobre Sandoz $\left.{ }^{\circledR}\right)$, tebuconazole (Folicur $\left.{ }^{\circledR}\right)$, sulfato de estreptomicina + oxitetraciclina (Agrimicina $\left.{ }^{\circledR}\right)$, oxitetraciclina + sulfato tribásico de cobre (Agrimaicin $\left.{ }^{\circledR}\right)$, $\operatorname{cartap}\left(\right.$ Caartap $\left.{ }^{\circledR}\right)$ e Fenthion (Lebaycid®), sob orientação dos técnicos da Maguari (Kraft Foods do Brasil). A polinização artificial foi realizada durante os picos de florescimento pelo produtor e sua família. Foram avaliadas mensalmente, do plantio até as mesmas atingirem o arame, a altura das plantas, medindo-se a planta do colo ao ápice; o número de folhas pela contagem das mesmas; o diâmetro do caule na região da enxertia, do enxerto e do porta-enxerto que consistiu na mensuração abaixo, acima e na região da enxertia, utilizados para calcularse a relação enxerto/porta-enxerto.

\section{RESULTADOS E DISCUSSÃO}

O número de folhas variou significativamente para cada porta-enxerto, nos diferentes tempos, como esperado. Também variou significativamente, quando comparados os diferentes porta-enxertos a cada avaliação, exceto na última, aos três meses após o plantio. Observou-se que, do segundo para o terceiro mês, houve um decréscimo do número de folhas para os quatro tratamentos, o que pode significar uma perda de folhas por senescência natural e em consequência do ataque de alguma doença ou praga (Tabela 1). No caso em questão, houve grande contribuição de doenças da parte aérea, o que leva a ponderar que, sendo a folha um órgão destacável, o seu número não é uma característica muito estável para avaliarse o desenvolvimento, pois sofre várias influências. Desta forma, a adoção do número de internódios, como feito por Staveley e Wolstenholme (1990), seria uma forma de obterem-se resultados mais confiáveis e que melhor refletiriam o desenvolvimento da planta. Vale ainda ressaltar a grande suscetibilidade observada nas plantas sobre o porta-enxerto $P$. alata à bacteriose (Xanthomonas axonopodis pv. passiflorae), desde a fase de viveiro e persistindo no campo. Provavelmente, o porta-enxerto translocou alguma(s) substância(s) que conferiu suscetibilidade à copa, originalmente tolerante.

A altura das plantas, de forma geral, apresentou o mesmo comportamento que o número de folhas, diferindo significativamente para cada porta-enxerto nas diferentes avaliações, exceto nas duas últimas, para três tratamentos $(P$. edulis $\mathrm{f}$. flavicarpa, $P$. cincinnata e pé-franco). A exceção foi $P$. alata, que apresentou desenvolvimento muito lento em virtude da severidade do ataque e da dificuldade do controle da bacteriose; teve-se, inclusive, de substituir algumas mudas. Também, a cada avaliação, os porta-enxertos diferiram entre si, menos aos três meses, pois boa parte das plantas já havia atingido o arame ou estava próxima deste (Tabela 2). Vale ressaltar que o desempenho dos porta-enxertos, à exceção de $P$. alata e $P$. cincinnata, foi semelhante, observando-se maior velocidade de crescimento no segundo mês e redução desta velocidade no terceiro, provavelmente devido à redução das temperaturas com a chegada do inverno em junho. O P. cincinnata, a partir do mês de maio, apresentou velocidade constante de crescimento. Por outro lado, P. alata foi o que, durante todo o período avaliado, apresentou a menor velocidade de crescimento. Isso ocorreu devido à bacteriose que, quando controlada, permitiu pleno desenvolvimento às plantas deste porta-enxerto, assemelhando-se às mais vigorosas conforme também foi relatado por Nogueira Filho (2003), Nogueira Filho et al. (2005) e Silva et al. (2005).

As características diâmetro da região da enxertia, diâmetro do enxerto e diâmetro do porta-enxerto, em linhas gerais, apresentaram o mesmo comportamento. Apresentaram diferenças significativas para cada porta-enxerto nas diferentes avaliações. Em relação à evolução das mesmas, no decorrer do tempo, de início, os diferentes tratamentos apresentaram valores próximos nos cinco primeiros meses, mas a partir daí, as diferenças foram aumentando e formando uma tendência crescente com dois grupos. No primeiro grupo, pé-franco, $P$. edulis f. flavicarpa e $P$. caerulea alternaram-se, dependendo da característica em questão, e, no segundo grupo, P. gibertii, P.cincinnata e P. alata, sempre nesta ordem (Tabelas 3, 4 e 5). Vale ressaltar que, para os três diâmetros avaliados, o pé-franco apresentou, no início, os menores valores, mas, depois de algum tempo, passou a apresentar valores entre os maiores. Admitindo-se que o diâmetro da planta é um indicativo de vigor (MENEZES, 1990;KIMURA, 1994) e comparando os tratamentos entre si, pode-se dizer que as plantas de pé-franco, $P$. edulis f. flavicarpa e $P$. caerulea se mostraram mais vigorosas que as de $P$. gibertii, $P$. cincinnata e $P$. alata.

Outro parâmetro a ser considerado na avaliação do desenvolvimento no campo, de plantas enxertadas de maracujá, é a "boa relação" do diâmetro enxerto/porta-enxerto, ou seja, que o desenvolvimento do diâmetro do enxerto seja proporcional ao do porta-enxerto a fim de permitir bom equilíbrio na circulação de seiva e, consequentemente, contribuir para o bom desempenho da planta enxertada. De modo geral, admite-se que uma "boa relação" do diâmetro 
enxerto/porta-enxerto ocorre quando a razão entre um e o outro atinge valores bem próximos de 1 , ou seja, quanto mais próximo de 1 for a razão do diâmetro enxerto/porta-enxerto, melhor será a relação entre eles (MENEZES, 1990).

A relação enxerto/porta-enxerto comportouse como as características anteriores, ou seja, apresentou diferenças significativas tanto para cada porta-enxerto, nas diferentes avaliações realizadas, como entre os porta-enxertos para cada avaliação realizada (Tabela 6). De forma geral, esta característica mostrou uma tendência decrescente de valores com o passar do tempo; para todos os porta-enxertos, o comportamento foi semelhante no décimo mês, incluindo o pé-franco, que não sofreu o processo da enxertia (Figura 06). Vale ainda ressaltar que a forma de enxertia aqui praticada é realizada na região hipocotiledonar próxima ao colo da planta; assim sendo, as medidas para o diâmetro do porta-enxerto foram efetuadas próximas ao colo da planta. Em se observando uma planta de maracujá, nota-se, com o passar do tempo, um vigoroso engrossamento natural do caule na região próxima ao colo da planta. Por isso, observou-se o comportamento decrescente para péfranco e, de maneira análoga, para os porta-enxertos. Então, este comportamento observado deveu-se muito mais aos locais de onde foram tomadas as medidas dos diâmetros do enxerto e do porta-enxerto, que a uma incompatibilidade propriamente dita.

À luz dos resultados obtidos por outros autores (OLIVEIRA et al.,1983; SEIXAS et al., 1987; MALDONADO, 1991; STENZEL;CARVALHO, 1992) para características de desenvolvimento, podese dizer que os resultados aqui são coincidentes e seguem na mesma direção. Ou seja, a planta enxertada pode ter menor desenvolvimento que a de pé-franco, de acordo com a espécie de maracujazeiro nativo utilizada como porta-enxerto. Isto está de acordo com o que foi relatado por Nogueira Filho (2003), Nogueira Filho et al. (2005), Silva et al. (2005), Lima et al. (2006) e Junqueira et al. (2006), que observaram o desenvolvimento e a influência do porta-enxerto sobre a variedade enxertada.

TABELA 1 - Número de folhas das plantas de maracujazeiro-amarelo produzidas por enxertia hipocotiledonar em plântulas de cinco espécies de passifloras silvestres, em pomar comercial, no período de 10-04-2002 a 10-07-2002, em Araguari - MG.

\begin{tabular}{|c|c|c|c|c|c|c|c|}
\hline \multirow{2}{*}{ Porta-enxerto } & \multicolumn{7}{|c|}{ Meses após o plantio no campo } \\
\hline & 00 & & 01 & 02 & & & 3 \\
\hline Pé-fi & $2,27^{1}$ & $\mathrm{Ba}(5,25)^{2}$ & $2,79 \mathrm{ABb}(8$ & $3,67 \mathrm{ABa}$ & $(1)$ & $3,20 \mathrm{Aa}$ & $(12$ \\
\hline ılea & 1,99 & $\mathrm{Ba}(4$ & $2,72 \mathrm{ABb}(7,75)$ & $3,24 \mathrm{Aa}$ & $(12,17)$ & $3,45 \mathrm{Aa}$ & $(12,83)$ \\
\hline P. cil & 2,24 & $\mathrm{BCa}($ & $3,39 \mathrm{ABa}(11,58)$ & $3,45 \mathrm{Aa}$ & $(13,00)$ & $1,99 \mathrm{Ca}$ & $(7,08)$ \\
\hline P. gibertii & 2,14 & $\mathrm{Ba}(4$, & $2,71 \mathrm{ABb}(7,58)$ & $3,66 \mathrm{Aa}$ & $(13,75)$ & $2,36 \mathrm{Ba}$ & $(9,58)$ \\
\hline P. flavicart & 2,12 & $\mathrm{Ba}(4,58)$ & $2,74 \mathrm{ABb}(7,75)$ & $3,70 \mathrm{Aa}$ & $(14,00)$ & $1,58 \mathrm{Ba}$ & $(6,08)$ \\
\hline P. alata & 1,64 & $\mathrm{Bb}(2,75)$ & $2,00 \mathrm{ABc}(4,17)$ & $2,29 \mathrm{ABb}$ & $(6,17)$ & 2,61 Aa & $(7,20)$ \\
\hline Geral & 2,07 & $(4,39)$ & $(7,81)$ & 3,37 & $(12,15)$ & 2,49 & $(9,33)$ \\
\hline
\end{tabular}

${ }^{1}$ Dados transformados em $\sqrt{ } \chi$.

${ }^{2}$ Dados não transformados

- Médias seguidas de mesma letra, maiúscula na horizontal e minúscula na vertical, não diferem significativamente, pelo teste de Tukey, a $5 \%$.

TABELA 2 - Altura (cm) das plantas de maracujazeiro-amarelo produzidas por enxertia hipocotiledonar em plântulas de cinco espécies de passifloras silvestres, em pomar comercial, no período de 10-04-2002 a 10-07-2002, em Araguari - MG.

\begin{tabular}{ccccc}
\hline \multirow{2}{*}{ Porta-enxerto } & \multicolumn{4}{c}{ Meses após o plantio no campo } \\
\cline { 2 - 5 } & $\mathbf{0 0}$ & $\mathbf{0 1}$ & $\mathbf{0 2}$ & $\mathbf{0 3}$ \\
\hline P. flavicarpa & $49,21 \mathrm{Ba}$ & $74,92 \mathrm{Bab}$ & $126,83 \mathrm{Aa}$ & $157,42 \mathrm{Aa}$ \\
P. cincinnata & $45,42 \mathrm{Ba}$ & $91,92 \mathrm{Aa}$ & $113,50 \mathrm{Aa}$ & $132,83 \mathrm{Aa}$ \\
P. gibertii & $43,04 \mathrm{Cab}$ & $67,08 \mathrm{Cbc}$ & $110,75 \mathrm{Ba}$ & $157,25 \mathrm{Aa}$ \\
P. caerulea & $32,58 \mathrm{Cb}$ & $52,08 \mathrm{Ccd}$ & $99,08 \mathrm{Ba}$ & $158,50 \mathrm{Aa}$ \\
Pé-franco & $14,79 \mathrm{Bc}$ & $34,83 \mathrm{Bd}$ & $90,33 \mathrm{Aab}$ & $129,58 \mathrm{Aa}$ \\
P. alata & $32,92 \mathrm{Ab}$ & $36,75 \mathrm{Ad}$ & $39,83 \mathrm{Ab}$ & $51,60 \mathrm{Ab}$ \\
\hline Geral & 36,33 & 59,60 & 96,72 & 133,47 \\
\hline
\end{tabular}

- Médias seguidas de mesma letra, maiúscula na horizontal e minúscula na vertical, não diferem significativamente, pelo teste de Tukey, a $5 \%$. 
TABELA 3 - Diâmetro da região da enxertia (mm) das plantas de maracujazeiro-amarelo produzidas por enxertia hipocotiledonar em plântulas de cinco espécies de passifloras silvestres, em pomar comercial, no período de 10-04-2002 a 10-02-2003, em Araguari - MG.

\begin{tabular}{|c|c|c|c|c|c|c|c|}
\hline \multirow{2}{*}{ Mês } & \multicolumn{6}{|c|}{ Porta-enxerto } & \multirow{2}{*}{ Gera } \\
\hline & P. flavicarpa & P. caerulea & Pé-franco & P. gibertii & P. cincinnata & P. alata & \\
\hline 00 & $5,27 \mathrm{Af}$ & 4,67 Ah & $2,39 \mathrm{Bg}$ & $5,22 \mathrm{Ae}$ & $4,78 \mathrm{Ag}$ & $4,49 \mathrm{Ac}$ & 4,55 \\
\hline 01 & $5,60 \mathrm{Af}$ & 4,91 ABgh & $3,41 \mathrm{Cg}$ & $5,63 \mathrm{Ae}$ & 5,60 Afg & $4,66 \mathrm{Bc}$ & 4,97 \\
\hline 02 & 6,82 Aef & 5,85 ABCgh & $5,09 \mathrm{BCfg}$ & $6,40 \mathrm{ABe}$ & 6,79 Aefg & $4,98 \mathrm{Cc}$ & 5,91 \\
\hline 03 & 9,77 Aef & 8,44 ABfg & 7,44 ABefg & 8,73 ABde & 8,79 ABdefg & $5,93 \mathrm{Bc}$ & 8,25 \\
\hline 04 & 12,86 Ade & 12,09 Aef & 10,67 ABdefg & 12,27 Acd & 10,73 ABcdef & 7,24 Bbc & 11,04 \\
\hline 05 & 16,13 Acd & 15,51 Ade & 14,54 ABcdef & 14,17 ABbcd & 12,07 ABbcde & 9,73 Bbc & 13,82 \\
\hline 06 & $18,35 \mathrm{Acd}$ & $17,07 \mathrm{Ad}$ & 16,53 Abcde & $14,20 \mathrm{ABbcd}$ & 12,46 ABbcd & $10,00 \mathrm{Bbc}$ & 14,84 \\
\hline 07 & $20,58 \mathrm{Abc}$ & $21,26 \mathrm{Ac}$ & 19,20 ABabcd & $16,95 \mathrm{ABbc}$ & $14,55 \mathrm{ABbc}$ & $11,96 \mathrm{Babc}$ & 17,60 \\
\hline 08 & $24,62 \mathrm{Aab}$ & $24,87 \mathrm{Abc}$ & 23,09 ABabc & $19,52 \mathrm{ABab}$ & 16,93 ABab & 14,93 Bab & 20,85 \\
\hline 09 & 28,29 Aba & $27,31 \mathrm{Aab}$ & 26,27 ABab & $23,47 \mathrm{ABa}$ & $20,42 \mathrm{Ba}$ & $19,10 \mathrm{Ba}$ & 24,93 \\
\hline 10 & $29,72 \mathrm{Aa}$ & $30,83 \mathrm{ABa}$ & $27,33 \mathrm{ABa}$ & $23,72 \mathrm{ABa}$ & $21,02 \mathrm{ABa}$ & $19,69 \mathrm{Ba}$ & 24,94 \\
\hline
\end{tabular}

- Médias seguidas de mesma letra, maiúscula na horizontal e minúscula na vertical, não diferem significativamente, pelo teste de Tukey, a $5 \%$.

TABELA 4 - Diâmetro da região do enxerto $(\mathrm{mm})$ das plantas de maracujazeiro-amarelo produzidas por enxertia hipocotiledonar em plântulas de cinco espécies de passifloras silvestres, em pomar comercial, no período de 10-04-2002 a 10-02-2003, em Araguari - MG.

\begin{tabular}{|c|c|c|c|c|c|c|c|}
\hline \multirow{2}{*}{ Mês } & \multicolumn{6}{|c|}{ Porta-enxerto } & \multirow{2}{*}{ Feral } \\
\hline & P. flavicarpa & Pé-franco & P. caerulea & P. gibertii & $P$. cincinnata & P. alata & \\
\hline 00 & $3,58 \mathrm{ABf}$ & $2,32 \mathrm{Cf}$ & $3,54 \mathrm{ABf}$ & $3,90 \mathrm{Ag}$ & $4,04 \mathrm{Ag}$ & $3,10 \mathrm{Bd}$ & 3,41 \\
\hline 01 & $4,06 \mathrm{ABf}$ & $3,27 \mathrm{CDf}$ & $3,77 \mathrm{BCf}$ & $4,13 \mathrm{ABg}$ & 4,64 Afg & 3,11 Dd & 3,83 \\
\hline 02 & 5,69 Aef & 4,85 ABef & 4,82 & 5,22 Afg & 5,85 Aefg & $\mathrm{Bd}$ & 4,98 \\
\hline 03 & 7,71 Aef & 7,38 Adef & $6,50 \mathrm{ABef}$ & 7,11 Aefg & 7,13 Adefg & $4,27 \mathrm{Bd}$ & 6,75 \\
\hline 04 & 10,45 Ade & 10,02 Acdef & 9,09 Ade & 9,32 Adefg & 8,68 Adef & $5,01 \mathrm{Bcd}$ & 8,82 \\
\hline 05 & 13,47 Acd & 12,73 Abcde & $11,70 \mathrm{Acd}$ & 10,99 Acdef & 9,60 ABcde & $6,28 \mathrm{Bcd}$ & 10,93 \\
\hline 06 & 15,49 Acd & 15,17 Abed & $13,57 \mathrm{Ac}$ & 12,67 Acde & 10,35 ABcde & 7,04 Bbcd & 12,45 \\
\hline 07 & $17,79 \mathrm{Abc}$ & 17,36 Aabc & $17,02 \mathrm{Ab}$ & $14,18 \mathrm{ABbcd}$ & 11,52 ABbcd & $8,52 \mathrm{Bbcd}$ & 14,62 \\
\hline 08 & $21,52 \mathrm{Aab}$ & $21,74 \mathrm{Aab}$ & $21,50 \mathrm{Aa}$ & 16,69 ABabc & $13,82 \mathrm{ABabc}$ & 11,11 Babc & 18,02 \\
\hline 09 & $24,35 \mathrm{ABa}$ & $24,84 \mathrm{Aa}$ & $23,40 \mathrm{ABa}$ & $18,77 \mathrm{ABCab}$ & $15,82 \mathrm{BCab}$ & $13,27 \mathrm{Cab}$ & 20,32 \\
\hline 10 & $26,27 \mathrm{Aa}$ & $25,62 \mathrm{ABa}$ & $23,55 \mathrm{ABCa}$ & $20,30 \mathrm{ABCa}$ & $17,34 \mathrm{BCa}$ & $15,37 \mathrm{Ca}$ & 21,64 \\
\hline
\end{tabular}

- Médias seguidas de mesma letra, maiúscula na horizontal e minúscula na vertical, não diferem significativamente, pelo teste de Tukey, a $5 \%$. 
TABELA 5 - Diâmetro do porta-enxerto ( $\mathrm{mm}$ ) das plantas de maracujazeiro-amarelo produzidas por enxertia hipocotiledonar em plântulas de cinco espécies de passifloras silvestres, em pomar comercial, no período de 10-04-2002 a 10-02-2003, em Araguari - MG.

\begin{tabular}{|c|c|c|c|c|c|c|c|}
\hline \multirow{2}{*}{ Mês } & \multicolumn{6}{|c|}{ Porta-enxerto } & \multirow{2}{*}{ Geral } \\
\hline & P.caerulea & P. flavicarpa & Pé-franco & P. gibertii & P. cincinnata & P. alata & \\
\hline 00 & $3,53 \mathrm{Bf}$ & $3,97 \mathrm{ABg}$ & $2,35 \mathrm{Cg}$ & 4,19 Ah & $4,01 \mathrm{ABf}$ & $3,43 \mathrm{ABc}$ & 3,61 \\
\hline 01 & $3,64 \mathrm{BCDf}$ & 4,38 ABCfg & 3,62 CDfg & 4,68 Ah & $4,43 \mathrm{ABf}$ & $3,65 \mathrm{Dc}$ & 4,03 \\
\hline 02 & 5,51 Af & 5,96 Afg & 5,31 ABfg & 6,03 Agh & 5,81 Aef & $3,68 \mathrm{Bc}$ & 5,38 \\
\hline 03 & 8,28 Aef & 8,49 Aefg & 7,57 ABefg & 8,30 Afgh & 7,17 ABef & $5,18 \mathrm{Bc}$ & 7,56 \\
\hline 04 & 11,10 Ade & 11,11 Adef & 10,34 Adefg & 10,40 Aefg & 8,73 ABdef & $5,81 \mathrm{Bc}$ & 9,65 \\
\hline 05 & 14,84 Acd & 15,18 Acde & 14,35 Acdef & 12,93 ABdef & 10,13 ABcde & 7,78 Bbc & 12,68 \\
\hline 06 & $17,32 \mathrm{Abc}$ & $16,71 \mathrm{ABcd}$ & 17,35 Abcde & 15,13 ABcde & 10,54 BCcde & $8,30 \mathrm{Cbc}$ & 14,31 \\
\hline 07 & $20,91 \mathrm{Ab}$ & $19,99 \mathrm{ABbc}$ & 20,72 Aabcd & $16,47 \mathrm{ABCbcd}$ & $12,37 \mathrm{BCbcd}$ & $10,78 \mathrm{Cabc}$ & 17,08 \\
\hline 08 & $26,07 \mathrm{Aa}$ & 24,04 ABab & 24,07 Aabc & $19,38 \mathrm{ABCabc}$ & 14,68 BCabc & $14,05 \mathrm{Cab}$ & 20,66 \\
\hline 09 & $30,24 \mathrm{Aa}$ & $25,90 \mathrm{ABab}$ & $26,63 \mathrm{ABab}$ & 21,50 ABab & 17,36 Bab & $16,88 \mathrm{Ba}$ & 23,25 \\
\hline 10 & $30,28 \mathrm{Aa}$ & $28,91 \mathrm{ABa}$ & $29,54 \mathrm{Aa}$ & $22,41 \mathrm{ABa}$ & $19,06 \mathrm{Ba}$ & $18,67 \mathrm{Ba}$ & 25,00 \\
\hline
\end{tabular}

- Médias seguidas de mesma letra, maiúscula na horizontal e minúscula na vertical, não diferem significativamente, pelo teste de Tukey, a $5 \%$.

TABELA 6. Relação enxerto/porta-enxerto $(\mathrm{mm})$ das plantas de maracujazeiro-amarelo produzidas por enxertia hipocotiiedonar em plântulas de cinco espécies de passifloras silvestres, em pomar comercial, no período de 10-04-2002 a 10-02-2003, em Araguari - MG.

\begin{tabular}{|c|c|c|c|c|c|c|c|}
\hline \multirow[t]{2}{*}{ Mês } & \multicolumn{6}{|c|}{ Porta-enxerto } & \multirow{2}{*}{ - Geral } \\
\hline & P. cincinnata & P. flavicarpa & Pé-franco & P. gibertii & P. caerulea & P. alata & \\
\hline 00 & $1,019 \mathrm{ABa}$ & $0,916 \mathrm{ABa}$ & $0,995 \mathrm{ABa}$ & 0,937 ABa & 1,030 Aab & $0,853 \mathrm{Ba}$ & 0,958 \\
\hline 01 & $1,057 \mathrm{ABa}$ & $0,938 \mathrm{ABCa}$ & 0,911 BCabc & $0,886 \mathrm{Ca}$ & $1,067 \mathrm{Aa}$ & $0,909 \mathrm{Ca}$ & 0,962 \\
\hline 02 & $1,022 \mathrm{Aa}$ & 0,962 Aa & 0,922 Aabc & $0,868 \mathrm{Aa}$ & 0,907 Aabc & 0,944 Aa & 0,937 \\
\hline 03 & $1,014 \mathrm{Aa}$ & $0,913 \mathrm{ABCa}$ & 0,967 ABab & $0,864 \mathrm{BCa}$ & $0,802 \mathrm{Cc}$ & $0,841 \mathrm{BCa}$ & 0,902 \\
\hline 04 & $1,030 \mathrm{Aa}$ & $0,945 \mathrm{ABa}$ & 0,965 ABab & $0,906 \mathrm{ABa}$ & $0,835 \mathrm{Bbc}$ & $0,881 \mathrm{Ba}$ & 0,928 \\
\hline 05 & $0,963 \mathrm{Aa}$ & $0,891 \mathrm{ABa}$ & 0,891 ABabc & $0,856 \mathrm{ABa}$ & $0,805 \mathrm{Bc}$ & $0,833 \mathrm{ABa}$ & 0,875 \\
\hline 06 & 0,992 Aa & $0,935 \mathrm{ABa}$ & 0,888 ABbc & $0,844 \mathrm{ABa}$ & $0,794 \mathrm{Bc}$ & $0,883 \mathrm{ABa}$ & 0,890 \\
\hline 07 & $0,943 \mathrm{Aa}$ & $0,896 \mathrm{Aa}$ & $0,851 \mathrm{Ac}$ & $0,869 \mathrm{Aa}$ & $0,843 \mathrm{Abe}$ & $0,786 \mathrm{aA}$ & 0,868 \\
\hline 08 & $0,952 \mathrm{Aa}$ & $0,913 \mathrm{ABa}$ & 0,907 ABabc & $0,873 \mathrm{ABa}$ & $0,840 \mathrm{ABbc}$ & $0,793 \mathrm{Ba}$ & 0,884 \\
\hline 09 & $0,922 \mathrm{ABa}$ & $0,947 \mathrm{Aa}$ & 0,947 Aabc & $0,867 \mathrm{ABa}$ & $0,793 \mathrm{Bc}$ & $0,828 \mathrm{ABa}$ & 0,888 \\
\hline 10 & $0,925 \mathrm{Aa}$ & $0,918 \mathrm{Aa}$ & 0,881 Abe & $0,898 \mathrm{Aa}$ & $0,794 \mathrm{Ac}$ & $0,839 \mathrm{Aa}$ & 0,879 \\
\hline Geral & 0,985 & 0,925 & 0,921 & 0,879 & 0,866 & 0,857 & 0,907 \\
\hline
\end{tabular}

- Médias seguidas de mesma letra, maiúscula na horizontal e minúscula na vertical, não diferem significativamente, pelo teste de Tukey, a 5\%. 


\section{CONCLUSÕES}

1-As plantas de P. edulis f. flavicarpa, $P$. caerulea e pé-franco apresenta melhor desenvolvimento (número de folhas, altura e diâmetro de plantas).

2-As plantas do porta-enxerto $P$. alata são as de pior desenvolvimento.

3-O número de folhas é uma característica que, no maracujazeiro, pode sofrer muitas variações devido a fatores não inerentes ao crescimento, sendo assim melhor a adoção de outro parâmetro, como número de internódios.

4-A melhor relação enxerto/porta-enxerto é da espécie $P$. cincinnata, embora as plantas de péfranco, $P$. edulis f. flavicarpa e $P$. caerulea tenham superado o seu desenvolvimento.

\section{REFERÊNCIAS}

BRUCKNER, C.H.; MELETTI, L.M.M.; OTON, W.C.; ZERBINI JÚNIOR, F.M. Maracujazeiro. In: BRUCNER, C.H. (Ed.). Melhoramento de fruteiras tropicais. Viçosa: Universidade Federal de Viçosa, 2002. p. 373-409.

CHAVES, R. da C.; JUNQUEIRA, N.T.V.; MANICA, I.; PEIXOTO, J.R.; PEREIRA, A.V.; FIALHO, J.F. Enxertia de maracujazeiro-azedo em estacas herbáceas enraizadas de espécies de passifloras nativas. Revista Brasileira Fruticultura, Jaboticabal, v.26, n.1, p.120-3, 2004.

JUNQUEIRA, N.T.V.; LAGE, D.A. da C.; BRAGA, M.F.; PEIXOTO, J.R.; BORGES, T.A.; ANDRADE, S.R.M. de. Reação a doenças e produtividade de um clone de maracujazeiro-azedo propagado por estaquia e enxertia em estacas herbáceas de Passiflora silvestre. Revista Brasileira de Fruticultura, Jaboticabal, v.28, n.1, p.97-100, 2006.

KIMURA, A. Estudo da enxertia hipocotiledonar de plântulas em Passiflora edulis Sims f. flavicarpa Deg. 1994. 56 f. Monografia (Trabalho de graduação em Agronomia) - Faculdade de Ciências Agrárias e Veterinárias, Universidade Estadual Paulista, Jaboticabal, 1994.
LIBERATO, J. R. Controle das doenças causadas por fungos, bactérias e nematoides em maracujazeiro. In: ZAMBOLIM, L.; VALE, F.X.R.; MONTEIRO, A.J.A.; COSTA, H. Controle de doenças de plantas: fruteiras. Viçosa: Universidade Federal de Viçosa, 2002. v.2, p.699-825.

LIMA, A.A.; CALDAS, R.C.; CUNHA, M.A.P.; SANTOS FILHO, H.P. Avaliação de porta-enxertos e tipos de enxertia para o maracujazeiro-amarelo. Revista Brasileira de Fruticultura, Jaboticabal, v.21, n.3, p.318-321, 1999.

LIMA, A. de A.; CALDAS, R.C.; SANTOS, V. da S. Germinação e crescimento de espécies de maracujá. Revista Brasileira de Fruticultura, Jaboticabal, v.28, 2006.

MALDONADO, J.F.M. Utilização de porta-enxertos do gênero Passiflora para o maracujazeiro-amarelo (Passiflora edulis Sims f. flavicarpa Deg.). Revista Brasileira de Fruticultura, Jaboticabal, v. 13, n. 2, p. 51-54, 1991.

MENEZES, J.M.T. Seleção de porta-enxertos tolerantes à morte prematura de plantas para $P$. edulis Sims f. fíavicarpa Deg. e comportamento de $P$. nitida H.B.K, na região de Jaboticabal. 1990. 73f. Dissertação (Mestrado em Melhoramento Genético Vegetal) - Faculdade de Ciências Agrárias e Veterinárias, Universidade Estadual Paulista, Jaboticabal, 1990.

MENEZES, J.M.T.; OLIVEIRA, J.C. de; RUGGIERO, C.; BANZATTO, D.A. Avaliação da taxa de pegamento de enxertos de maracujá-amarelo sobre espécies tolerantes à „,morte prematura de plantas". Científica, São Paulo, v. 22, n. 1, p. 95104, 1994.

NOGUEIRAFILHO, G.C. Enxertia hipocotiledonar de maracujazeiro-amarelo em diferentes espécies de passifloras silvestres. 2003. $119 \mathrm{f}$. Tese (Doutorado em Agronomia)- Faculdade de Ciências Agrárias e Veterinárias, Universidade Estadual Paulista, Jaboticabal, 2003.

NOGUEIRA FILHO, G.C.; RONCATTO, G.; RUGGIERO, C.; OLIVEIRA, J.C.; MALHEIROS, E.B. Propagação vegetativa do maracujazeiroconquista de novas adesões. In: FALEIRO, F.G.; JUNQUEIRA, N.T.V.; BRAGA, M.F. (Ed.). Maracujá: germoplasma e melhoramento genético. Planaltina: Embrapa Cerrados, 2005, p. 340-358. 
SIDRA/IBGE - Sistema IBGE de Recuperação Automática/Instituto Brasileiro de Geografia e Estatística. Produção Agrícola Municipal de 2007: maracujá. Brasília: Ministério do Planejamento, Orçamento e Gestão. Disponível em: <http:// www.sidra.ibge.gov.br/bda/tabela/protabl. asp? $\mathrm{c}=1613 \& \mathrm{z}=\mathrm{p} \& \mathrm{o}=22 \& \mathrm{i}=\mathrm{P}>$. Acesso em: 13 maio 2009.

SILVA, F.M.; CORREA, L. de S.; BOLIANI, A. C.; SANTOS, P. C. dos.Enxertia de mesa de Passiflora edulis Sims f. flavicarpa Deg. sobre Passiflora alata Curtis, em ambiente de nebulização intermitente. Revista Brasileira de Fruticultura, Jaboticabal, v.27, n.1, p.98, 2005.

STAVELEY, G.W.; WOLSTENHOLME, B.N. Effects of water stress on growth and flowering of Passiflora edulis Sims grafted to $P$. caerulea L. Acta Horticulturae, The Hague, n. 275, p. 551-558, 1990.
STENZEL, N.M.C.; CARVALHO, S.L.C. Comportamento do maracujazeiro-amarelo (Passiflora edulis Sims f. flavicarpa Deg.) enxertado sobre diferentes porta-enxertos. Revista Brasileira de Fruticultura, Jaboticabal, v.14, n.3, p. 183-186, 1992.

VAN RAIJ, B.; CANTARELLA, H.; QUAGGIO, J. A.; FURLANI, A.M.C. (Ed.). Recomendações de adubação e calagem para o Estado de São Paulo. Campinas: Instituto Agronômico de Campinas, 1997. 285p. (Boletim Técnico, 100). 